Pacific Journal of Mathematic 


\title{
ON A CHARACTERISTIC PROPERTY OF FINITE SETS
}

\author{
G. KUREPA
}

1. Introduction. There are several equivalent definitions of finite sets [2], [5]. The purpose of this note is to give an equivalent property of finite sets in terms of ramifications of sets.

DEFINITION 1. A partially ordered set $S \equiv(S ; \leq)$ is said to be ramified or to satisfy the ramification condition ([3], pp.69, 127; cf. 4) provided that for every $x \in S$ the set $(-\infty, x)$ of all $y \in S$ satisfying $y<x$ is totally ordered (that is, contains no distinct noncomparable points). If the points of a ramified set $(S ; \leq)$ are the same as these of a set $M$, one says that $(S ; \leq)$ is a ramification of $M$.

DEFINITION 2. A chain (anti-chain) of a partially ordered set $(S ; \leq)$ is any subset of $S$ containing no distinct incomparable (comparable) points. Every set containing a single point is considered both as chain and as anti-chain.

DEFINITION 3. For a partially ordered set $(S ; \leq)=S$, we denote by

$$
O(S) \text { or } O S
$$

the system of all maximal chains contained in $S$; analogously,

$$
\bar{O}(S) \text { or } \bar{O} S
$$

denotes the system of all maximal anti-chains of $S$.

THEOREM. In order that a nonvoid set $S$ be finite, it is necessary and sufficient that for every ramification $T(S)$ of $S$ the relations

$$
M \in O T(S), \quad A \in \bar{O} T(S)
$$

imply

$$
M \cap A \neq \Lambda \quad(\Lambda \equiv \text { vacuous set }) .
$$

Received January 7, 1952.

Pacific J. Math. 2 (1952), $323-326$ 
2. The condition is necessary. Otherwise, there would be a finite set $S$, a ramification $T(S)$, a set $M \in O T(S)$, and a set $A \in \overline{O T}(S)$, such that

$$
M \cap A=\Lambda \text {. }
$$

Now, $A$ is a maximal anti-chain of $T(S)$; consequently, for every $x \in T(S)$ there is a point $a(x) \in A$ such that the set $\{x, a(x)\}$ is a chain of $T(S)$. (Otherwise, the set $A \cup\{x\}$ would be an anti-chain greater than the maximal antichain $A$. )

In particular, for any $x \in M \in O T(S)$, the points $x, a(x)$ are comparable. We say that

$$
x<a(x) \text {. }
$$

Since $M$ is a maximal chain of the ramified set $T(S), M$ is an initial portion of $T(S)$; that is, $M$, which contains the point $x$ contains also every point of $T(S)$ preceding $x$. In particular, if (6) did not hold then $M$ would contain also $a(x) \leq$ $x$; consequently, $a(x) \in M \cap A$, contrary to the assumption (5).

Thus if (5) held then for every $x \in M$ one would have (6); but $M$, as a nonvoid subset of the finite set $T(S)$, would have a terminal point, say $l ; l$ would be a final point of $T(S)$, too, contrary to the relation (6) for $x=l$. Thus the relation (5) is not possible.

3. The condition is sufficient. If for every ramification $T(S)$ the relations (3) imply (4), then the set $S$ is finite. Otherwise, the set $S$ would be infinite; consequently, there would be a one-to-one correspondence $\phi$ of the set $N$ of all natural numbers into $S$. Now, let us define the ordering $(S ; \leq)$ by transplantation of a certain order of the set $N$. We shall order $N$ according to the scheme ${ }^{1}$,

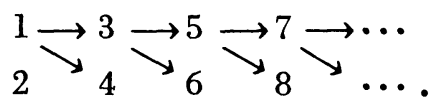

That is, the set $2 N-1$ of all $2 n-1(n \in N)$ is ordered as in the natural order; for every $n \in N$, the set of numbers preceding $2 n$ consists of the numbers $2 \nu-1(\nu=1,2, \cdots, n)$; all other couples of natural integers are incomparable, by definition. In the ramified set $N_{0}$ so obtained one sees that $2 N \in \bar{O} N_{0}$, that $2 N-1 \in O N_{0}$, and that the sets $2 N, 2 N-1$ are disjoint. Now, the set $S$ being infinite by hypothesis, there is a one-to-one mapping $\phi$ of $N=N_{0}$ into $S$. p.6].

${ }^{1}$ For the definition of schemes or diagrams of partly ordered sets see Birkhoff $[1$, 
That enables us to define the order in $S$ by transporting the order of $N_{0}$ into $S$ so that, on the one hand, the mapping $\phi$ is a similitude between $N_{0}$ and $\phi N_{0} \subseteq$ $S$, and so that, on the other hand, no point of $\phi N_{o}$ is comparable to any point of $S \backslash \phi N_{0}$, and so that $S \backslash \phi N_{0}$ contains no comparable couple of distinct points.

It is obvious that the set $(S ; \leq)$ is ramified, that the set $\phi(2 N-1)$ is a maximal chain of $(S ; \leq)$, and that the set $A=\phi(2 N) \cup(S \backslash \phi N)$ is a maximal anti-chain of $(S ; \leq)$.

According to (4), the set $A \cap \phi(2 N-1)$ would be nonvacuous, contrary to the fact that the sets $A, \phi(2 N-1)$ are disjoint.

Thus, the proof of the theorem is completed.

4. Observation. We observe that the condition of ramification in the statement of the theorem is essential. Namely, if we consider the partially ordered set $S_{1}=\{1,2,3,4,5\}$ with the diagram

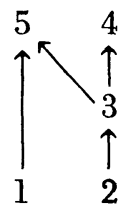

it is obvious that $\{2,3,5\}$ is a maximal chain of $S$, that $\{1,4\}$ is a maximal anti-chain of $S$, and that the set $\{2,3,5\}$ does not intersect the set $\{1,4\}$.

5. Questions. In connection with the statement of the theorem it is interesting to consider the following two questions:

QUESTION 1. Is there a partially ordered nonvacuous set $S$ such that there is no maximal anti-chain $A \in \bar{O} S$ satisfying $A \cap M \neq \Lambda$ for every maximal chain $M \in O S$ ?

QUESTION 2. Is there a partially ordered nonvacuous set $S$ such that there is no maximal chain $M \in O S$ satisfying $M \cap A \neq \Lambda$ for every maximal anti-chain $A \in \bar{O} S$ ?

\section{REFERENCES}

1. G. Birkhoff, Lattice theory, New York, 1948.

2. K. Iseki, Sur les ensembles finis, C. R. Acad. Sci. Paris 231 (1951), 1396-1397.

3. G. Kurepa, Ensembles ordonnés et ramifiés, Thèse, Paris, 1935; Publ. Math. Univ. Belgrade 4(1935), 1-138.

4. L'hypothese de ramification, C. R. Acad. Sci. Paris 202 (1936), 185-187. 
5. A. Tarski, Sur les ensembles finis, Fund. Math. 6 (1924), 45-95.

Mathematics INSTItUTE OF THE UNIVERSITY Zagreb, Yugosla via 


\title{
PACIFIC JOURNAL OF MATHEMATICS
}

\section{EDITORS}

\section{R. M. RobINSON \\ University of California \\ Berkeley 4, California}

\author{
*R. P. Dilwor TH \\ California Institute of Technology \\ Pasadena 4, California
}

\author{
E. F. BECKENBACH, Managing Editor \\ University of California \\ Los Angeles 24, California
}

${ }^{*}$ During the absence of Herbert Busemann in 1952.

\section{ASSOCIATE EDITORS}

$\begin{array}{llll}\text { R. P. DILWORTH } & \text { P. R. HALMOS } & \text { B } \emptyset \text { RGE JESSEN } & \text { J. J. STOKER } \\ \text { HERBERT FEDERER } & \text { HEINZ HOPF } & \text { PAUL LÉVY } & \text { E. G. STRAUS } \\ \text { MARSHALL HALL } & \text { R. D. JAMES } & \text { GEORGE PÓLYA } & \text { KÖSAKU YOSIDA }\end{array}$

\section{SPONSORS}

UNIVERSITY OF BRITISH COLUMBIA

CALIFORNIA INSTITUTE OF TECHNOLOGY

U NIVERSITY OF CALIFORNIA, BERKELEY

UNIVERSITY OF CALIFORNIA, DAVIS

UNIVERSITY OF CALIFORNIA, LOS ANGELES

UNIVERSITY OF CALIFORNIA, SANTA BARBARA

OREGON STATE COLLEGE

UNIVERSITY OF OREGON

\author{
UNIVERSITY OF SOUTHERN CALIFORNIA \\ STANFORD UNIVERSITY \\ WASHINGTON STATE COLLEGE \\ UNIVERSITY OF WASHINGTON \\ AMERICAN MATHEMATICAL SOCIETY \\ NATIONAL BUREAU OF STANDARDS, \\ INSTITUTE FOR NUMERICAL ANALYSIS
}

Mathematical papers intended for publication in the Pacific Journal of Miathematics should be typewritten (double spaced), and the author should keep a complete copy. Manuscripts may be sent to any of the editors. All other communications to the editors should be addressed to the managing editor, E. F. Beckenbach, at the address given above.

Authors are entitled to receive 100 free reprints of their published papers and may obtain additional copies at cost.

The Pacific Journal of Mathematics is published quarterly, in March, June, September, and December, by the University of California, Berkeley 4, California. The price per volume (4 numbers) is $\$ 8.00$; single issues, $\$ 2.50$. Special price to individual faculty members of supporting institutions and to individual members of the American Mathematical Society: $\$ 4.00$ per volume; single issues, $\$ 1.25$.

Subscriptions, orders for back numbers, and changes of address should be sent to the publishers, University of California Press, Berkeley 4, California.

Printed at Ann Arbor, Michigan. Entered as second class matter at the Post Office, Berkeley, California.

\section{UNIVERSITY OF CALIFORNIA PRESS • BERKELEY AND LOS ANGELES}




\section{Pacific Journal of Mathematics}

\section{Vol. 2, No. $3 \quad$ March, 1952}

Lars V. Ahlfors, Remarks on the Neumann-Poincaré integral equation .... 271

Leonard P. Burton, Oscillation theorems for the solutions of linear, nonhomogeneous, second-order differential systems ............ 281

Paul Civin, Multiplicative closure and the Walsh functions . . . . . . . . . . . 291

James Michael Gardner Fell and Alfred Tarski, On algebras whose factor algebras are Boolean .................................. 297

Paul Joseph Kelly and Lowell J. Paige, Symmetric perpendicularity in Hilbert geometries .................................. 319

G. Kurepa, On a characteristic property of finite sets .............. 323

Joseph Lehner, A diophantine property of the Fuchsian groups ......... 327

Donald Alan Norton, Groups of orthogonal row-latin squares ........... 335

R. S. Phillips, On the generation of semigroups of linear operators ....... 343

G. Piranian, Uniformly accessible Jordan curves through large sets of relative harmonic measure zero ........................ 371

C. T. Rajagopal, Note on some Tauberian theorems of $O . S z \tilde{A} ; s z \ldots \ldots \ldots 377$

Halsey Lawrence Royden, Jr., A modification of the Neumann-Poincaré method for multiply connected regions .................... 385

George H. Seifert, A third order irregular boundary value problem and the associated series ...................................... 395

Herbert E. Vaughan, Well-ordered subsets and maximal members of ordered sets....

Hans F. Weinberger, An optimum problem in the Weinstein method for eigenvalues.

Shigeki Yano, Note on Fourier analysis. XXXI. Cesàro summability of Fourier series. 